\title{
A PRÁTICA E O ENSINO DE ENFERMAGEM EM SAÚDE MENTAL E PSIQUIÁTRICA NO BRASIL: QUESTÕES PARA REFLEXÕES ${ }^{1}$ \\ [Practice and teaching of mental health and psychiatric nursing in Brazil: thought-provoking Issues]
}

Mariluci Alves Maftum* Márcia Bicchi Alencastre ${ }^{\star \star}$

\begin{abstract}
RESUMO: Nesse estudo teve-se como objetivos conhecer aspectos que permearam a trajetória da prática assistencial e do Ensino de Enfermagem em Saúde Mental e Psiquiátrica ao longo do percurso do ensino de enfermagem em geral. Fazer algumas reflexões sobre o papel da enfermagem psiquiátrica no enfoque da reforma vigente no Brasil, que está embasada no modelo humanista italiano. As idéias de humanistas como Baságlia e Rotelli sobre a assistência ao portador de sofrimento psíquico vêm contribuindo para um novo direcionamento no cuidado e no ensino de enfermagem, no qual a palavra do paciente é valorizada e não utilizada como forma de punição. A cidadania é perseguida de modo a garantir os direitos de assistência, trabalho e espaço político social. São privilegiadas outras formas e extensões de tratamento e prevenção além do hospital. Essas mudanças imprimem uma necessidade de repensar e reavaliar o papel que os profissionais de enfermagem desempenham dentro da equipe de saúde e na academia.
\end{abstract}

PALAVRAS-CHAVE: Educação; Saúde mental; Enfermagem psiquiátrica.

\section{INTRODUÇÃO}

Visitar o passado, refletir sobre o presente para poder questionar e vislumbrar aspectos do futuro do ensino de enfermagem da temática saúde mental e psiquiátrica no enfoque humanista, eis o que motivou a realização desse estudo bibliográfico bem como a apresentação das reflexões

\footnotetext{
Capítulo da tese intitulada "O Ensino de Enfermagem em Saúde Mental e Psiquiátrica no Paraná" que está sendo desenvolvida junto ao Programa Interunidades de Doutoramento em Enfermagem da EERP/EE-USP.

* Professora do Curso Técnico em Enfermagem da Escola Técnica da UFPR. Doutoranda do Programa Interunidades de Doutoramento da EERP/EE-USP.

** Professora do Departamento de Enfermagem Psiquiátrica e Ciências Humanas da Escola de Enfermagem de Ribeirão Preto da Universidade de São PauloEERP-USP. Doutora em Enfermagem. Orientadora

2 O termo Reforma Psiquiátrica será utilizado, neste trabalho, para designar a reforma vigente com base no modelo democrático iniciado por Franco Baságlia em Trieste, província italiana.
}

que dele emergiram. Para dar sustentação teórica a esta investigação foi necessário recorrer a autores que se ocuparam em estudar tal assunto e refletir sobre a Reforma Psiquiátrica ${ }^{2}$ em andamento no Brasil.

Cumpre ressaltar que não há aqui a pretensão de se fazer um tratado sobre a história do ensino desse tema, tampouco relatar o movimento da Reforma Psiquiátrica, porque outros estudos mais completos sobre tais aspectos já existem, como os de pesquisadores de vários Estados do Brasil: FERNANDES (1982); ARANTES (1973); STEFANELLI (1981); STEFANELLI (1993); BRAGA (1993); BRAGA, (1998); MIRANDA (1994); BARROS (1996); KANTORSKI (1998); ALENCASTRE (2000). A intenção foi conhecer um pouco a prática e o processo ensino-aprendizagem da Enfermagem em Saúde Mental Psiquiátrica no Brasil, como vem ocorrendo ao longo da trajetória do ensino de enfermagem como um todo.

\section{A PRÁTICA E O ENSINO DE ENFERMAGEM EM SAÚDE MENTAL E PSIQUIÁTRICA NO CONTEXTO DA ENFERMAGEM}

A profissão de enfermagem tem seu início marcado pela organização da prática e do ensino, na segunda metade do século XIX, mais precisamente em 1860, por Florence Nightingale, na Inglaterra, no período da rainha Vitória. Suas idéias e práticas, consideradas em todo o mundo uma verdadeira reforma da enfermagem - a revolução de Nightingale - qualificaram-na como a primeira enfermeira moderna. No Brasil, a reforma iniciou-se no começo do século $X X$, mais especificamente, em 1923 com a criação da Escola de enfermagem Ana Neri, no Rio de Janeiro, pautada nos princípios nightingaleanos (MIRANDA, 1994; ALCÂNTARA, 1966).

Desde a organização da enfermagem como profissão no Brasil até nossos dias, várias têm sido as lutas e as conquistas dos profissionais, tanto na ampliação e no reconhecimento de um espaço de atuação junto à equipe de saúde e à sociedade, como também na estruturação do currículo dos três níveis que compõem a enfermagem brasileira - graduação, técnico e auxiliar. BARROS (1996, p. 52) diz que 
"o desenvolvimento da enfermagem psiquiátrica como campo específico do saber tem sido influenciado pelo movimento da enfermagem, que avança de acordo com as mudanças que acontecem na sociedade e nas ciências médicas".

Apesar de a criação da Escola de Enfermagem Ana Neri ser considerada pela maioria dos profissionais de enfermagem o marco inicial da enfermagem brasileira, em 1890 foi criada no Brasil a primeira Escola para Enfermeiros e Enfermeiras, junto ao Hospício D. Pedro II, no Rio de Janeiro. Fundamentada no modelo francês, tinha por objetivo formar mão-de-obra para atender alienados. MIRANDA (1994) assinala essa como uma primeira tentativa de sistematização do ensino de enfermagem e afirma que, num paradoxo, a primeira escola foi estruturada junto ao hospício para assistir o "louco", mas este foi "esquecido" por longo tempo pelas escolas de enfermagem modernas fundadas posteriormente.

No que se refere ao ensino de Enfermagem em Saúde Mental e Psiquiátrica, MIRANDA (1994) assinala que a primeira tentativa de sistematização do ensino de enfermagem no Brasil ocorreu com o surgimento da primeira escola estruturada junto ao hospício para assistir o "louco", mas, em um paradoxo, este foi "esquecido" por um longo tempo pelas escolas de enfermagem modernas fundadas posteriormente.

A autora enfatiza que as primeiras grades curriculares da Escola Ana Néri incluíam a disciplina "Arte de Enfermagem em Doenças Mentais e Nervosas". Apesar de essa disciplina constar, em 1926, no Regimento Interno do Departamento Nacional de Saúde Pública (DNSP) do Serviço de Enfermeiras, em análise de currículo de aluno de 1925, ela está riscada e escrita "doença venérea" e juntamente com depoimentos de ex-alunas participantes do seu estudo "Parentesco imaginário", é possível observar que o ensino de enfermagem acontecia sem o ensino de enfermagem psiquiátrica. Afirma também que, a partir de 1940 o ensino de enfermagem psiquiátrica era ministrado de forma simular. Um psiquiatra ministrava a parte teórica (patologias, síndromes psiquiátricas), de acordo com o modelo organicista francês e alemão, e uma enfermeira lecionava a parte prática, que consistia praticamente no ensino de higiene, técnicas de contenção física e administração de medicamentos. A disciplina previa, também, rápidas visitas a hospícios, o que contribuía para provocar pânico e afastar as estudantes da enfermagem psiquiátrica.

O segundo currículo mínimo de enfermagem, conforme Lei 775 , de 6 de agosto de 1949, entre as suas vinte e nove disciplinas havia "Enfermagem em Clínica Neurológica e Psiquiátrica", com estágio obrigatório (FERNANDES, 1982; GERMANO, 1985; BRAGA, 1993).

BARCELLOS (1951, p. 86) chama a atenção para a importância do ensino de enfermagem psiquiátrica nos cursos e corrobora o descaso e a desassistência ao doente mental em nosso país, em trabalho apresentado no IV Congresso Nacional de Enfermagem em Salvador, sob o título "A enfermagem psiquiátrica". Diz ela:

A enfermagem psiquiátrica é um ramo da enfermagem que não é novo; no entanto, mesmo nos países onde ela está atualmente bem desenvolvida como nos Estados Unidos e Inglaterra, somente há um quarto de século mais ou menos sua importância foi reconhecida pelos médicos e o público em geral. Em nosso meio, embora ela esteja incluída no programa de algumas escolas de enfermagem, foi introduzida no currículo das escolas em geral como obrigatória só muito recentemente pela Lei $n^{\circ} 775$, que regulamenta o ensino nas Escolas de Enfermagem do Brasil.

MIRANDA (1994, p. 92) chama-nos a atenção para esse "desassistir" do doente mental, ao afirmar "do louco asilado não se sabe a idade, o sexo, a profissão, as causas da internação, nem quais os tratamentos estaria recebendo para alcançar a cura acenada", referindo-se à inexistência de arquivos nos hospícios.

Em minha prática como docente, quando indagamos aos profissionais de saúde de maior tempo de serviço sobre os documentos dos antigos internos das instituições campos de estágios, informam-nos que os "prontuários" nada acrescentam ao estudo, pois, quando muito, trazem o nome do paciente, um número e prescrição médica de eletrochoque, contenção física em caso de agitação psicomotora e manutenção da medicação.

Em seu trabalho "O Parentesco Imaginário", MIRANDA (1994, p. 103) traz à tona duas constatações importantes para reflexões sobre a história da enfermagem psiquiátrica, tanto no Brasil como em outros países: "a enfermagem moderna, implantada por Florence Nightingale no século XIX, não incluía o louco na clientela a ser assistida por nurses", o mesmo também ocorreu, pelo menos no período de 1923-1926, no currículo da Escola de Enfermagem Ana Nery implantada no Brasil, que só passou a desenvolver estágio nessa disciplina em 1949, no Hospício Engenho de Dentro.

Esta autora continua afirmando que não acredita ter a enfermagem psiquiátrica nascido mal no Brasil pelo fato de a primeira escola que sistematizou o ensino dessa área não ter sido pautada no modelo Nightingale e que o equívoco não foi na estrutura pedagógica, mas na concepção coletiva da época sobre a doença mental e sobre o doente mental, tendo como pano de fundo questões político-ideológicas. O enfermeiro psiquiátrico não surgiu para viabilizar uma melhoria na assistência ao louco, mas para ajudar a tornar científico o discurso psiquiátrico brasileiro dentro dos hospícios. 
BARROS (1996) diz que na época da organização da enfermagem como profissão pautada nas idéias de Florence, Tuke e Pinel já haviam instituído o tratamento moral; assim, o louco já ocupava lugar no discurso médico psiquiátrico. A prática assistencial ao alienado, que Pinel preconizou no final do século XVIII, permitiu inferir que o papel dos profissionais que cuidavam dos alienados naquela época incluía as ações como isolar, disciplinar e punir.

O Sistema Nightingale foi implantado nos Estados Unidos (EUA), no ano de 1873, com a criação de três escolas. Nove anos mais tarde, 1882, criou-se a primeira escola de enfermagem com enfoque psiquiátrico no McLean Hospital, cuja finalidade era melhorar a assistência aos doentes mentais. A escola treinava os atendentes que trabalhavam em hospitais psiquiátricos (BARROS, 1996).

Naquela época, as enfermeiras que recebiam treinamento assistiam o médico nos procedimentos com o paciente, administrando drogas sedativas como "whisky" e clorofórmio; cuidavam da higiene, aplicavam balneoterapia duchas frias ou quentes, banhos contínuos e aplicação de compressas (BARROS, 1996).

Com o movimento psicodinâmico no início do século $\mathrm{XX}$, a psicanálise e o tratamento psicanalítico chegaram como nova forma de assistir o doente mental. Sua característica era o tratamento em consultórios particulares. Assim pareceu não afetar os enfermeiros, que não viam espaço para atuarem no tratamento de um paciente em análise (BARROS, 1996).

A partir de 1930, surgiram os tratamentos biológicos (sonoterapia, insulinoterapia, psicocirurgia, eletroconvulsoterapia), dando à enfermagem psiquiátrica um novo campo de atuação, pela necessidade do preparo e cuidado do paciente para o recebimento dessas práticas (KAPLAN \& SADOCK, 1993; MIRANDA, 1994; BARROS, 1996).

Após 1940, "sob a influência de Harry Stack Sullivan, que defendia a teoria de que a doença mental resulta essencialmente de uma perturbação das relações interpessoais", enfermeiras norte-americanas começaram a preocupar-se em melhor qualificar-se, não somente na execução de técnicas de tratamento somáticos, mas também nas técnicas psicoterápicas usadas pelos psiquiatras. Assim, a enfermeira como PEPLAU (1952), introduziu o relacionamento terapêutico como o principal instrumento para a atuação dos profissionais de enfermagem psiquiátrica, influenciando também o ensino de enfermagem nos cursos de graduação do Brasil (BARROS, 1996, p. 56).

No Brasil, o ensino do relacionamento terapêutico nos cursos de enfermagem foi introduzido, a partir de 1968, pelas enfermeiras Arantes e Stefanelli, como apontam os trabalhos ARANTES (1973); ARANTES (1979); STEFANELLI (1981); STEFANELLI (1985); STEFANELLI e ARANTES (1985), seguidos por outros profissionais de enfermagem tanto no estímulo ao ensino e à prática assistencial como na pesquisa.

MAFTUM (2000, p. 2), com base em STEFANELLI (1993), enfatiza que os conteúdos que dão base ao desenvolvimento do relacionamento e comunicação terapêutica entre enfermeiro e paciente fazem "parte da essência do ser humano e que é a mola mestra da enfermagem". Portanto esses temas devem ser inerentes e permear todas as fases do currículo dos cursos de Enfermagem, não se restringindo aos momentos ou disciplinas destinadas à Enfermagem em Saúde Mental e Psiquiátrica.

Como até 1962 o ensino de enfermagem era de nível médio, somente a partir desse ano, por meio do parecer 271/ 62 do Conselho Federal de Educação, é que se tornou educação superior, surgindo um novo currículo e, entre as oito disciplinas obrigatórias, uma era a Enfermagem Psiquiátrica (BRAGA, 1993; SOUZA 1995).

Como já mencionamos anteriormente nesta investigação, várias foram as reformas do ensino de Enfermagem ocorridas até hoje. Quanto à área da Enfermagem em Saúde Mental e Psiquiátrica, discute-se carga horária teóricoprática, campo de estágio, momento em que a disciplina deve ocorrer, se o discurso ideológico acadêmico é reproduzido na prática ou se há dissonância entre ambos, se deve haver ênfase no relacionamento interpessoal e na comunicação etc. Para certo conforto, hoje se vê a disciplina sedimentada, já reconhecida como importante na formação dos profissionais da área da enfermagem, que necessitam aprender e saber usar os conhecimentos que embasam a compreensão do ser humano, nas motivações e comportamentos, bem como interagir com o paciente no momento crítico de sofrimento mental.

Confirmando as reflexões acima, FERNANDES (1982) chama-nos a atenção para a Reforma do currículo de Enfermagem de 1972, que decorreu também das exigências da Reforma Universitária de 1968. Explicita que docentes de enfermagem, através de encontros, seminários e congressos com o intuito de estudar o currículo do curso e estabelecer diretrizes para o aperfeiçoamento do corpo docente, elaboraram sugestões que, transformadas em anteprojeto do currículo mínimo, foram enviadas através da $A B E n$, ao Conselho Federal de Educação. O Anteprojeto culminou no parecer 163/72 da Comissão Central de Revisão dos Currículos e Aprovada pela Resolução n. ${ }^{\circ} 4$ de 25 de fevereiro de 1972.

O currículo passou a constituir-se de três partes sucessivas: pré-profissional, tronco profissional comum específico à formação do enfermeiro e habilitações opcionais em enfermagem obstétrica, enfermagem de saúde pública ou enfermagem médico-cirúrgica. A última habilitação contida no 
parecer 163/72, causou surpresa, uma vez que o anteprojeto da ABEn não a incluía. A surpresa maior não foi o fato de mais essa oferta para a formação de enfermeiros, mas por não terem sido possibilitadas outras habilitações, como a de enfermagem pediátrica e psiquiátrica.

Sob essa ótica, estudos das enfermeiras PEPLAU (1952); TRAVELBEE (1982); ARANTES (1979) e STEFANELLI (1981), nos quais afirmam que o profissional de enfermagem psiquiátrica pode desenvolver o relacionamento terapêutico com o paciente, e que este passou a ser considerado instrumento básico de atuação do enfermeiro em Saúde Mental e Psiquiátrica (BARROS, 1996), são de extrema importância.

Atualmente, com o movimento da Reforma Psiquiátrica, novos modos de assistir passaram a integrar o tratamento do doente mental. Isso suscita uma reflexão profunda dos docentes dessa área, incluindo análise dos currículos, para que estes propiciem a formação de enfermeiros bem informados e conscientes do papel terapêutico que têm junto ao doente mental.

À medida que a enfermagem vai escrevendo sua trajetória, procurando firmar-se como profissão perante a sociedade, amplia seus horizontes e busca respostas às suas inquietações, esse movimento mostra-se de diversas formas e se reflete em todas as áreas, nos currículos mínimos implantados até hoje (1923, 1949, 1962, 1972) (BRAGA, 1993).

É marcante o discurso atual entre os docentes sobre a humanização da assistência, a totalidade do ser, a integralidade, a interdisciplinaridade, a relação pessoa-pessoa e a transdisciplinaridade. Contudo percebe-se ainda a vigência de currículos de Enfermagem que privilegiam o modelo biomédico, habilitando o profissional para atuar nas necessidades físicas e biológicas, centradas na doença e não no doente.

As idéias de humanistas como Baságlia e Rotelli, na assistência do doente mental proporcionam novo direcionamento no cuidado de enfermagem, no qual a palavra do paciente é valorizada e não mais utilizada como forma de punição. A cidadania é perseguida de modo a garantir os direitos de assistência, trabalho e espaço político e social. São privilegiadas outras formas e extensões de tratamento e prevenção, além do hospital.

BRAGA (1998, p.7) alerta, entretanto: "apesar de a proposta de Reforma Psiquiátrica mostrar-se como momento oportuno para o repensar de questões, antigas e novas, sobre o processo saúde/doença mental e a forma de abordar e assistir os indivíduos, poucas são as mudanças observadas e frágil é o engajamento dos envolvidos (pacientes, familiares e profissionais)".

A Reforma Psiquiátrica que vem acontecendo está contribuindo na ampliação do campo de atuação do enfermeiro nessa área, mas esse profissional precisa desenvolver competências e habilidades na abordagem e no relacionamento com o doente. $\mathrm{O}$ enfoque atual assume o caráter humanístico e social de construção da cidadania, o doente mental sendo sujeito no processo de saúde e doença. Nessa concepção, "o objeto da psiquiatria torna-se então não mais a periculosidade e a doença, mas a 'existênciasofrimento' dos pacientes e sua relação com o corpo social". Assim, ganha destaque a pessoa que está sofrendo e não a doença que o faz sofrer; a doença é colocada em suspensão, ou seja, é deixada temporariamente de lado para que se possa ver, ouvir, perceber a pessoa. Isso não significa negar a existência da enfermidade, mas ela não vem na frente, não é a principal causa de intervenção do profissional, porque o foco de interesse é o doente (NICÁCIO, 1990, p. 99).

GOLDBERG (1996, p. 40) ressalta que, na nova proposta, "procura-se acolher e valorizar aquilo que é mais desvalorizado pelo entorno social dessas pessoas, que é o conteúdo de suas falas", e que "a função mais importante é receber cada pessoa do jeito que ela é, e garantir sua particularidade".

Essas mudanças refletem-se diretamente na prática e no ensino de enfermagem, uma vez que suscitam um repensar em toda sua formação e atuação. Para que isso ocorra é importante haver flexibilidade e abertura, com vistas a apreender as necessidades de redimensionamento nas formas de tratamentos, em compreensão mais profunda a respeito do que permeia a vida do doente mental.

BARROS (1996) considera que a Reforma Psiquiátrica ora em andamento imprime o desenho de um novo modelo de assistência, no qual a premissa fundamental é a cidadania do usuário do serviço. Ressalta também que essa proposta está assentada em princípios como democratização dos serviços, universalização e eqüidade tal como a Reforma Sanitária em geral e para esse novo enfoque impera a necessidade de ruptura com o paradigma manicomial.

A "desinstitucionalização é um processo social complexo: não é um processo linear, passível de ser administrado igualmente em todas as regiões independente de forças e resistências político-econômicas e dos atores sociais" (ROTELLI, 1990; NICÁCIO, s/d, p. 98).

PONTES et al. (1995) consideram que, a partir de 1979, se iniciou um redirecionamento na tendência hospitalocêntrica de assistência psiquiátrica com a chamada Reforma Psiquiátrica, que tem estes objetivos: desativação progressiva dos hospitais psiquiátricos; substituição deles por um sistema extra-hospitalar e multiprofissional de assistência; resgate da cidadania do doente mental; reinserção da saúde mental em outros programas e instituições de saúde.

Os diferentes entendimentos da assistência e seus paradigmas têm colaborado para que a Reforma Psiquiátrica 
esteja acontecendo de forma não linear e homogênea (AMARANTE, 1994), a passos lentos em alguns estados, cidades e hospitais, pois ela está ocorrendo em diferentes regiões e municípios simultaneamente e caminha de acordo com as concepções culturais e com a correlação de forças de trabalho e política existentes.

Nos últimos anos tem havido empenho por parte dos dirigentes governamentais e de alguns profissionais da saúde, como WAIDMAN, (1998); PITA, (1996); BERTOLOTE, (1996), no processo de reabilitação psicossocial e reinserção do doente mental na sociedade. Acredita-se que o doente fora do hospital consegue ter uma vida mais próxima da vida comum de qualquer cidadão, mesmo em casas denominadas "lares abrigados", "pensões protegidas" como as que surgiram em algumas cidades do país.

Em 2000, a Comissão Nacional de Reforma Psiquiátrica, criada em 1994, instituiu a portaria no 106: cria e estabelece os critérios para os Serviços Residenciais Terapêuticos em Saúde Mental no âmbito do Sistema Único de Saúde, para o atendimento ao portador de transtornos mentais (BRASIL, 2000).

A reabilitação psicossocial é, na essência, a remoção de barreiras que impedem a plena integração de uma pessoa na sua comunidade, o pleno exercício dos seus direitos e da sua cidadania. Entendemo-la como "a restituição plena dos direitos, das vantagens, das posições que estas pessoas tinham ou poderiam vir a ter, se lhes fossem oferecidas outras condições de vida, nas quais as barreiras fossem atenuadas ou desaparecessem" (BERTOLOTE, 1996, p. 156).

Percebem-se avanços ocorridos na assistência psiquiátrica brasileira desde o final da década de oitenta; porém somente no dia seis de abril de 2001 , após mais de dez anos de tramitação, o projeto de lei n. 3657/89, de autoria do Deputado Federal Paulo Delgado, transformou-se na Lei Federal n. 10.216 sancionada pelo Presidente da República Fernando Henrique Cardoso (BRASIL, 2001). Essa nova Lei Federal, que ficou conhecida como "Lei Paulo Delgado", propõe uma assistência à Saúde Mental no Brasil não mais baseada nos hospitais psiquiátricos, dispondo sobre a extinção progressiva dos manicômios e sua substituição por outros recursos assistenciais. Estabelece, ainda, direitos dos pacientes, limita e regulamenta as internações psiquiátricas. Veio substituir a legislação brasileira de 1934, que tratava, até então, da questão da assistência aos doentes mentais (BRASIL, 1934).

Os currículos dos cursos de graduação e a disciplina de Enfermagem em Saúde Mental e Psiquiátrica simultaneamente vêm sofrendo os impactos das mudanças ocorridas pela nova Lei de Diretrizes e Bases da Educação e do Movimento da Reforma Psiquiátrica no Brasil. Tais mudanças imprimem no momento algumas incertezas, dificuldades em ressignificar e redimensionar a prática profissional, tanto dos docentes quanto dos demais componentes da equipe de saúde mental, característica do momento de transição.

\section{CONSIDERAÇÕES FINAIS}

A Reforma Psiquiátrica que ora se está processando não diz respeito, exclusivamente, a medidas de caráter tecnocientífico ou organizacional, mas representa um processo permanente de construção de reflexões e transformações que ocorrem a um só tempo no campo assistencial, cultural e conceitual (AMARANTE, 1997). Enquanto construção social, ela não se dará apenas com o estabelecimento de leis, mas resultará do contínuo exercício da cidadania, com mudanças no íntimo de cada profissional e de cada cidadão.

Investir na melhoria da assistência do doente mental leva a crer que isso também importará a melhora de sua saúde, o que, por conseguinte, levará o paciente à longevidade e qualidade de vida, prerrogativas que deveriam ser asseguradas a todo o cidadão.

As mudanças vêm acontecendo muito lentamente $e$ com sérias dificuldades, pois envolvem o repensar de todo um processo que, por muitos anos, tem acontecido de forma muito limitada, visando quase só à internação e que, para a maioria dos pacientes, ocorre em locais distantes do seu meio de convívio.

Vislumbra-se acabar com as mazelas do doente mental tratando-o em ambulatórios, clínicas, bairros e unidades psiquiátricas de hospitais gerais. Idealiza-se um futuro em que os leitos psiquiátricos sejam distribuídos na comunidade, o que é a tendência em alguns países da Europa e também no Brasil. (MORGADO \& LIMA, 1995). Conquanto toda mudança ou reforma, por si só, gerem insegurança e stress, pois testar o desconhecido envolve esses sentimentos peculiares ao ser humano, quando bem analisada e discutida, sua condução tende a ser favorável, desde que as pessoas envolvidas se dediquem com seriedade e afinco a elas.

Muito embora sejam necessárias mudanças no repensar da prática para que haja avanços no processo de evolução da humanidade, elas deverão refletir preocupação com o coletivo, pois mudanças que correspondam a interesses de alguns podem transformar-se em catástrofes para os usuários e seus familiares. Isso reafirma que a problemática que envolve a área da saúde mental e da psiquiatria é de responsabilidade de todos, das múltiplas esferas: governamentais, acadêmicas, profissionais de saúde e educação, serviços prestadores de saúde e da comunidade em geral. 
O momento atual é de transição para muitos cursos no que diz respeito a organização curricular. Disso decorre que em alguns cursos o ensino de Enfermagem em Saúde Mental e Psiquiátrica esteja inserto em outras áreas de ensino, como nos casos de currículos integrados. Há também, em outros, a manutenção da modalidade disciplina, embora tenhamos percebido que há um movimento da maioria dos cursos na discussão e reorganização do ensino de modo geral, seja para atender as exigências da nova LDB e diretrizes curriculares BRASIL (1996) e BRASIL (2001) ou por demanda interna do corpo docente e discente.

MIRON et al. (2000) acreditam que todas a mudanças que vêm ocorrendo na área da assistência psiquiátrica se refletem no ensino de Enfermagem Psiquiátrica e Saúde Mental no país. Referem que, certamente, as salas de aula tornaram espaços nos quais as discussões podem ser travadas e que houve ampliação dos locais e modificação nas formas de intervenção de enfermagem, durante as atividades práticas das disciplinas da área, não se restringindo ao aprendizado em hospitais psiquiátricos. Esse redirecionamento deverá concretizar o papel terapêutico que os profissionais de enfermagem psiquiátrica tem no cuidado ao portador de sofrimento mental, diminuindo o enfoque predominante de uma prática quase restrita à execução de tarefas, como higiene, administração de medicamento e manutenção da ordem.

ABSTRACT: This study objectifies to unveil aspects that have permeated the trajectory of practice and teaching of Mental Health and Psychiatric Nursing throughout nursing teaching; to think over the role of psychiatric nursing under the reform in effect in Brazil, which is grounded by the Italian humanist model. Humanists' ideas such as Baságlia and Rotelli on caring rendered to the mental patient, have posed a new direction to nursing caring and teaching where patients' words are valued and not used as a way to punish them. Citizenship is pursued in order to ensure their rights to care, work and a political and social status. Other ways and contexts for treatment are privileged besides hospital settings. Such changes forward the need to rethink and reassess the role of nursing professionals in the health team and nursing faculty.

KEY WORDS: Education; Mental health; Psychiatric nursing.

\section{REFERÊNCIAS}

1 ALCÂNTARA, G. A enfermagem moderna como categoria profissional: obstáculos à sua expansão na sociedade brasileira. Rio de Janeiro: [s.n.], 1966.

2 ALENCASTRE, M. B. (Org.). Estudos sobre o ensino de enfermagem psiquiátrica e saúde mental no Brasil. Ijuí: UNIJUÍ, 2000.
3 AMARANTE, P. Loucura, cultura e subjetividade: conceitos e estratégias, percursos e atores da reforma psiquiátrica brasileira. In: Fleury, Sônia (Org.). Saúde e democracia: a luta do CEBES. São Paulo: Lemos Editorial, 1997. p. 163-185.

4 AMARANTE, P. (Org.). Psiquiatria social e reforma psiquiátrica. Rio de Janeiro: FIOCRUZ, 1994.

5 ARANTES, E. C. O ensino do relacionamento terapêutico em enfermagem psiquiátrica. Revista Brasileira de Enfermagem. Rio de Janeiro, v. 26, n. 6, 1973. p. 438-446.

6 ARANTES, E. C. et al. Relacionamento terapêutico: considerações teóricas e relato de uma experiência. Revista Escola de Enfermagem USP. São Paulo, v. 13, n. 3, 1979. p. 217-22338.

7 BARCELLOS, E. Enfermagem psiquiátrica. Anais de Enfermagem ABED. São Paulo, v. 3, n.1, jan. 1951.

8 BARROS, S. O louco, a loucura e a alienação institucional: o ensino de enfermagem psiquiátrica sub judice. Tese (Doutorado) Escola de Enfermagem, Universidade de São Paulo, São Paulo. São Paulo, 1996. 202 p.

9 BERTOLOTE, J. M. Em busca de uma identidade para a reabilitação psicossocial. In: PITTA, A. (Org.) Reabilitação psicossocial no Brasil. São Paulo: Hucitec, 1996. p. 155-158.

10 BRAGA, V. A. B. A enfermagem e a disciplina enfermagem psiquiátrica: visão da aluna. Dissertação (Mestrado) - Escola de Enfermagem de Ribeirão Preto, Universidade de São Paulo. São Paulo, 1993. $138 \mathrm{p}$.

11 BRAGA, V. A. B. O ensino de enfermagem psiquiátrica no Ceará e a reforma psiquiátrica: avanços e recuos. Tese (Doutorado) Escola de Enfermagem de Ribeirão Preto, Universidade de São Paulo. São Paulo,1998. 163 p.

12 BRASIL, Decreto-Lei n. 24.559 de 3 de julho de 1934. Dispõe sobre a profilaxia mental, assistência e a proteção à pessoa e aos bens dos psicopatas, à fiscalização dos serviços psiquiátricos e dá outras providencias. Atos do governo provisório, Rio de Janeiro, 1934. p. 351-360.

13 BRASIL, Lei n. 10.216 de 6 de abril de 2001. Dispõe sobre a proteção e os direitos das pessoas portadoras de transtornos mentais e redireciona o modelo assistencial em saúde mental. Disponível em: <http://www.saude.gov.br/sas/portarias.htm>. Acesso em: 7 nov. 2002.

14 BRASIL. Portaria n. 106 de 11 de fevereiro de 2000. Cria os Serviços Residenciais Terapêuticos em Saúde Mental, no âmbito do Sistema único de Saúde, para o atendimento ao portador de transtornos mentais. Disponível em: <http://www.saude.gov.br/sas/portarias.htm>. Acesso em: 7 nov. 2002.FERNANDES, Josicléia Dumet. Reflexão sobre a prática do ensino da enfermagem psiquiátrica e saúde mental. Rev. Bras. Enfermagem, Brasília, v. 32, n. 4, 1979. p. 403-406.

15 FERNANDES, Josicléia Dumet. Reflexão sobre a prática do ensino da enfermagem psiquiátrica e saúde mental. Rev. Bras. Enfermagem, Brasília, v. 32, n. 4, 1979. p. 403-406.

16 FERNANDES, Josicléia Dumet. O ensino da enfermagem e de enfermagem psiquiátrica no Brasil. Dissertação de Mestrado Universidade Federal da Bahia. Bahia, 1982. 111 p.

17 GERMANO, R. M. Educação e ideologia da enfermagem no Brasil 2. ed. São Paulo: Cortez, 1985.

18 GOLDBERG, J. Reabilitação como processo - o centro de atenção psicossocial-CAPS. In: PITTA, A. (Org.) Reabilitação psicossocial no Brasil. São Paulo: Hucitec, 1996. p. 33-47. 
19 KANTORSKI, L. P. O ensino de enfermagem psiquiátrica e saúde mental e a reforma psiquiátrica no Rio Grande do Sul. Tese (Doutorado) - Escola de Enfermagem Ribeirão Preto, Universidade de São Paulo. São Paulo, 1998. 214 p.

20 KAPLAN, H. I \& SADOCK, B. I. Compêndio de psiquiatria: ciências comportamentais. 6. ed. Porto Alegre: Artes Médicas Sul, 1993.

21 MAFTUM, Mariluci Alves. A comunicação terapêutica vivenciada por alunos do curso técnico em enfermagem. Dissertação de Mestrado - Pós Graduação em Enfermagem da Universidade Federal de Santa Catarina, Santa Catarina, 2000. 87 p.

22 MIRANDA, C. L. O parentesco imaginário: história e representação social da loucura nas relações do espaço asilar. São Paulo: Cortez, 1994.

23 MIRON, Véra Lúcia et al. Região Sul. In: ALENCASTRE, Marcia Bucchi. (Org.). Estudos sobre o ensino de enfermagem psiquiátrica e saúde mental no Brasil. Ijuí: UNIJUÍ, 2000. p. 110-144. Série Relatórios de Pesquisa.

24 MORGADO, A.; LIMA, L. A. Asilo e hospital psiquiátrico: ainda são necessários na era da saúde mental comunitária? J. Bras. Psiq., Rio de Janeiro, v. 44, n 11, nov. 1995. p. 551-558.

25 NICÁCIO, F. (Org.) Desinstitucionalização. São Paulo: Hucitec, 1990.

26 NICÁCIO, F. Da instituição negada à instituição inventada. In: LANCETTI, A. (Dir.) Saúde Loucura. 2. ed. São Paulo: Hucitec, s/d. p. 92-108.

27 PITTA, A. (Org.). Reabilitacão psicossocial no Brasil. São Paulo: Hucitec, 1996

28 PONTES, P. A. R. et al. Reforma psiquiátrica no Ceará: tópicos de caracterização dos novos serviços. Rev. Bras de Enf., Brasília, v. 48, n. 3, 1995. p. 297-303.
27 ROTELLI, F. A instituição inventada. In: NICÁCIO, F. (Org.). Desinstitucionalização. São Paulo: Hucitec; 1990. p. 89-99.

28 SOUZA M. C. B. M. Estudo bibliográfico da produção da enfermagem psiquiátrica no Brasil no período de 1932 a 1993. Dissertação (Mestrado) - Escola de Enfermagem de Ribeirão Preto, Universidade de São Paulo. São Paulo, 1995. 201 p.

29 STEFANELLI, M. C. Importância do processo de comunicação na assistência de enfermagem. Rev. Escola Enf. USP, São Paulo, v. 15, n. 3, 1981. p. 239-245.

30 STEFANELLI, M. C. Ensino de técnicas de comunicação terapêutica enfermeira-paciente. Tese (Doutorado) - Escola de Enfermagem, Universidade de São Paulo, São Paulo, 1985, 163 p.

31 STEFANELLI, M. C.; ARANTES, E. Cançado. Relacionamento terapêutico enfermeiro-paciente e comunicação terapêutica. Revista Escola Enfermagem USP, São Paulo, v.5, n.1, 1985. p. 42-44.

32 STEFANELLI, M. C.; ARANTES, E. Comunicação com paciente: teoria e ensino. 2. ed. São Paulo: Robe, 1993. 190 p.

33 WAIDMAN, M. A. P. Enfermeira e família compartilhando o processo de reinserção social do doente mental. Dissertação (Mestrado) - Pós Graduação em Enfermagem, Universidade Federal de Santa Catarina. Florianópolis, 1998. 109 p.

Endereço das autoras: Rua Clemente Tesserolli, 90 - Jd. das Américas 81520-190 - Curitiba - PR E-mail: ubiracy@terra.com.br 